\title{
Higher tropical SSTs strengthen the tropical upwelling via deep convection
}

\author{
R. Deckert ${ }^{1}$ and M. Dameris ${ }^{1}$ \\ Received 21 February 2008; accepted 2 April 2008; published 28 May 2008.
}

[1] Recent observations show a distinct cooling of the tropical lower stratosphere, and chemistry-climate models (CCMs) suggest a link to a strengthening tropical upwelling, arguably related to increases in greenhouse gas concentrations from anthropogenic activity. The present study explores the strengthening of tropical upwelling by comparing ensemble realisations of two different transient scenarios with the CCM E39/C. Both scenarios share the same boundary conditions, including concentrations of ozone-depleting substances, but differ in their climate forcing via prescribed sea surface temperatures (SSTs) and well-mixed greenhouse gas concentrations. In the summer hemisphere tropics, higher SSTs amplify deep convection locally and hence the convective excitation of quasistationary waves. These waves propagate upward through the region of easterly winds while dissipating, but still carry enough of the signal into the low-latitude lower stratosphere to induce an anomalous low-latitude Brewer-Dobson (BD) cell. The transport change in turn increases the flux of ozone-poor tropospheric air into the tropical lower stratosphere. Citation: Deckert, R., and M. Dameris (2008), Higher tropical SSTs strengthen the tropical upwelling via deep convection, Geophys. Res. Lett., 35, L10813, doi:10.1029/ 2008GL033719.

\section{Introduction}

[2] Thompson and Solomon [2005] detect a recent annual-mean cooling of the tropical lower stratosphere in radiosonde data which could refer to a combination of convective, radiative, and dynamical effects [Forster et $a l ., 2007]$. The existence of a dynamical contribution necessitated an upward mass transport intensification across the tropical tropopause. This would add to the cooling not only adiabatically but also radiatively, primarily because it would enhance the cross-tropopause transport of ozonepoor tropospheric air [Rind et al., 2002].

[3] While current observational data are insufficient to detect changes in the tropical upwelling [Thompson and Solomon, 2005] most current modeling studies agree in that it intensifies for a warming climate [e.g., Eyring et al., 2007; Fomichev et al., 2007; Butchart et al., 2006; Rind et al., 2002]; yet the reason for the intensification remains unknown. The present study explores a new causal hypothesis: higher tropical SSTs intensify the tropical upwelling due to a stronger deep-convective generation of quasi-stationary waves. These waves travel upward while dissipating but

\footnotetext{
${ }^{1}$ Deutsches Zentrum für Luft- und Raumfahrt, Institut für Physik der Atmosphäre, Wessling, Germany.
}

Copyright 2008 by the American Geophysical Union. 0094-8276/08/2008GL033719\$05.00 carry enough of the signal across the tropical tropopause to alter the upwelling via the principle of downward-control [Haynes et al., 1991].

[4] In their double $\mathrm{CO}_{2}$ investigations, Fomichev et al. [2007] and Rind et al. [2002] infer a pattern of enhanced eddy dissipation occurring in the tropical lower stratosphere. This pattern appears to accelerate the tropical upwelling by stimulating an anomalous BD cell locally. According to Fomichev et al. [2007] and Rind et al. [2002] the eddy dissipation enhancement mainly refers to higher tropical sea surface temperatures (SSTs). In this context, the importance of deep convective quasi-stationary eddy generation has probably not yet been acknowledged. Following Chen et al. [2001] and Chen [2001] these eddies can ascend through the tropical easterly winds and cross the tropopause.

[5] As far as we are aware, there are no studies that have considered both SST-induced modifications to the convection-related eddy dissipation in the tropical lower stratosphere and the associated implications for the BD circulation. Related studies are those by Kerr-Munslow and Norton [2006] and Boehm and Lee [2003], for instance, but the authors do not account for SST-related decadal changes.

[6] The hypothesis presented above is tested by an analysis of CCM simulations regarding the individual elements of the hypothesis and their connection.

\section{Description of Experiments and Methods}

[7] This study assesses ensemble realisations of two different scenarios with the CCM E39/C [Dameris et al., 2005]. Briefly, E39/C is a 39 layer spectral CCM with fully coupled chemistry. It has a horizontal resolution of T30, and its upper model lid is centered at $10 \mathrm{hPa}$.

[8] Both E39/C scenarios mentioned above share the same boundary conditions but differ in the prescription of greenhouse gas (GHG) concentrations and SSTs, allowing separation of GHG-related effects from those of the other forcings, e.g. ozone-depleting substances.

[9] The reference scenario (REF) and its realisations are presented by Dameris et al. [2006]. REF covers the period 2000-2019 and adopts the A1b "medium" scenario [Intergovernmental Panel on Climate Change, 2001] for GHGs and SSTs. The set of transient SSTs is taken from a run with the HADGEM1 atmosphere ocean general circulation model (AOGCM) [Stott et al., 2006]. The constant-climate scenario $(\mathrm{SCN})$ and its realisations are introduced by World Meteorological Organization [2007, section 5.3.7]. Covering the period 1980-2019, its GHGs are fixed at 1980 observed values; the transient SSTs are taken from observations made from 1970 to 1979 [Rayner et al., 2003], and are repeated for each of the four decades in 1980-2019. 


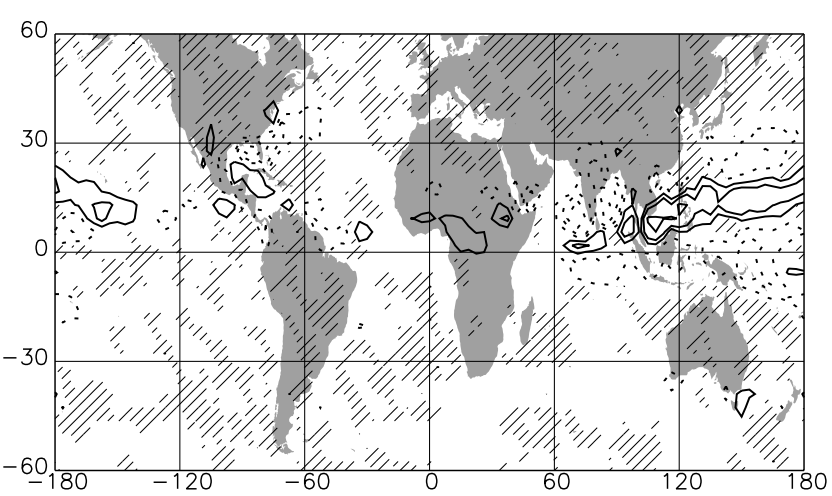

Figure 1. Rate of ensemble mean anomalous (REF minus SCN) surface convective precipitation for JA. Solid contours: positive anomalies. Dotted contours: negative anomalies. The contours denote values of $\pm 1.0, \pm 4.0, \pm 9.0$, \pm 16.0 (in $2 \times 10^{-9} \mathrm{~m} / \mathrm{s}$ ). Hatching marks regions where not all of the six individual anomalies have the same sign.

[10] The present study analyzes 20-year means of the model period 2000 to 2019 , using three realisations of REF, and two realisations of SCN. The robustness of the ensemble mean anomalies, REF minus SCN, is verified by a comparison of the six partially dependent anomalies associated with the individual ensemble members. An ensemble mean anomaly is considered as robust only if all of the six individual anomalies display similar patterns.

[11] Finally, the consideration of three realisations of an additional 1960-1999 transient scenario, designed to reproduce the past, demonstrates that the main findings of the present study do not mirror a systematic bias between observed and modeled SSTs; the additional scenario uses observed SSTs taken from Rayner et al. [2003]. A detailed scenario description and realisation evaluation is available in the work by Dameris et al. [2005].

\section{Results}

[12] The analyses presented in this section test the hypothesis that higher tropical SSTs strengthen the deepconvective latent-heat release (section 3.1), enhancing the tropical deep-convective eddy generation (section 3.2), and in turn modifying the tropical lower stratospheric BD circulation (section 3.3).

[13] For the sake of shortness and simplicity the results depicted are restricted to the northern hemisphere and are based on the two-monthly mean July-August (JA) when in our simulations the above effect is strongest. Note that we find the effect to be relevant also during June and September and that our simulations contain a similar effect in the southern hemisphere during the period December to March. The response of transient Eliassen-Palm (EP) quantities is not presented since results not shown here demonstrate unimportance with respect to the quasi-stationary case.

\subsection{Tropical SSTs and Deep Convection}

[14] The tropical SSTs for REF are higher than those for SCN, by a maximum of about $+1 \mathrm{~K}$ in the Western-Pacific region. Obviously, the higher SSTs mainly intensify the convective precipitation in the Western-Pacific rain band (Figure 1).
[15] The response patterns in tropical convective precipitation rates emerge as a positive anomaly in the pattern of zonal-mean anomalous latent heating rates (not depicted). Its height structure indicates that the modeled convective precipitation enhancement in the Western Pacific mainly results from deep convection. It is well known that deep convection constitutes the major trigger of tropical precipitation [e.g., Barsugli et al., 2006].

\subsection{Deep Convection and Generation of Quasi-Stationary Eddies}

[16] In their study, Horinouchi et al. [2003] briefly mention that tropical zonal-mean surface precipitation represents a useful indicator of zonal-mean deep-convective eddy forcing. As the deep-convective precipitation intensifies for the warmer climate of the present study (section 3.1) one would thus expect a greater forcing of quasi-stationary eddies; this section shows that this is indeed the case.

[17] There is a distinct tropical regime of anomalous EP divergence and EP flux inside the region of easterly winds (Figure 2). On close inspection, the EP flux arrows for all of the six individual anomalies point in similar directions thus indicating robustness. On the one hand, the anomalous EP regime displays order-of-magnitude lower values than its absolute counterparts (REF and SCN) which are not depicted. On the other hand, the positioning of positive/ negative EP divergence patterns and the EP flux directions

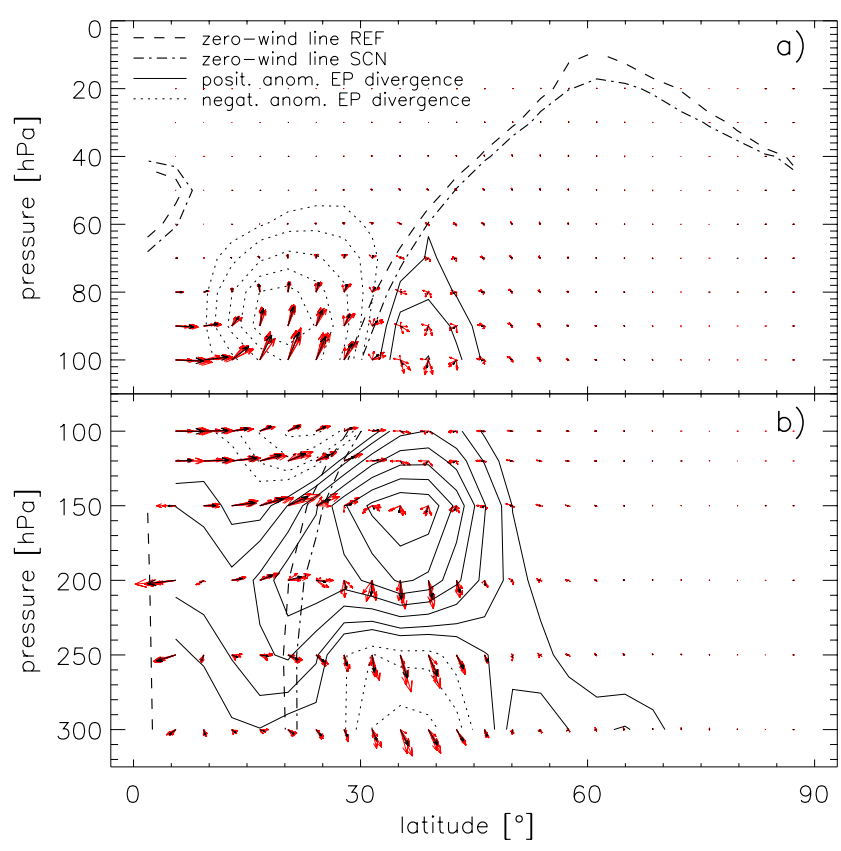

Figure 2. JA anomalous (REF minus $\mathrm{SCN}$ ) quasi-stationary EP diagnostics in the northern hemisphere. A horizontal EP flux arrow of the same length as $10^{\circ}$ latitude corresponds to $1.82 \times 10^{14} \mathrm{~m}^{3}$ (Figure 2a) and $1.02 \times 10^{14} \mathrm{~m}^{3}$ (Figure 2b), a vertical EP flux arrow of the same length corresponds to $4.68 \times 10^{18} \mathrm{~m}^{3} \mathrm{kPa}$ (Figure 2a) and $1.35 \times 10^{19} \mathrm{~m}^{3} \mathrm{kPa}$ (Figure 2b). Black arrows: ensemble mean anomalous EP flux. Red arrows: anomalous EP flux for each of the six individual anomalies. EP divergence is given in values of $\pm 1.0 \pm 2.0 \pm 3.5 \pm 5.0 \pm 6.5 \pm 8.0 \pm 9.5$ (in $10^{14} \mathrm{~m}^{3}$ ). Zonal winds at low latitudes are mostly easterly. 


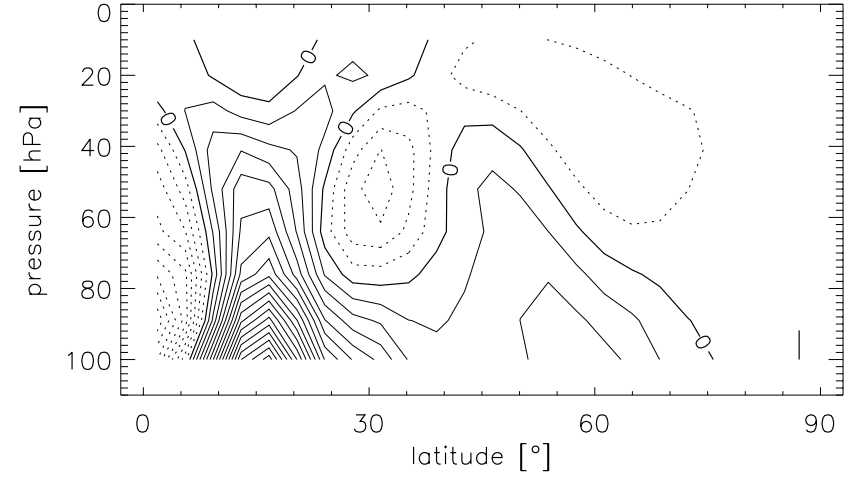

Figure 3. JA ensemble mean anomalous (REF minus SCN) TEM stream function (in $0, \pm 1, \pm 2, \pm 3, \ldots$ multiples of $\pm 10^{8} \mathrm{~kg} / \mathrm{s}$ ) in the northern hemisphere. Solid contours denote positive values, dotted contours negative values. The anomalous mass transport is parallel to the isolines, clockwise around a stream function maximum, counterclockwise around a minimum, and its strength proportional to the density of the isolines. Section 3.3 provides a discussion of robustness.

for the anomaly and the absolute resemble each other. The whole tropical regime hence intensifies for the warmer climate, the positive anomalous EP divergence pattern below $130 \mathrm{hPa}$ signifying a more intense production of quasi-stationary eddies. The eddies involved propagate into the tropical lower stratosphere while dissipating in the easterly winds, as indicated by the pattern of negative anomalous EP divergence above $150 \mathrm{hPa}$.

[18] There are strong arguments for both the tropical anomalous and absolute regimes referring to deep-convective eddy generation: the vertical extent of the tropospheric positive EP divergence pattern matches that of the respective deep-convective latent-heat release, the latter set to a maximum height of $130 \mathrm{hPa}$ in $\mathrm{E} 39 / \mathrm{C}$; seasonal cycles are not depicted, but our simulations show that the cycle of both regimes matches that of the respective northern-hemispheric tropical deep-convective latent-heat release, in accordance with findings for the absolute case by, e.g., Wang and Ting [1999] and Garcia and Salby [1987]; the anomalous regime is as robust as the SST-induced anomalous deep-convective latent-heat release. Finally, the extratropical anomalous quasi-stationary regime inside the westerly winds rather weakens for the warmer climate, hence is unlikely to contribute to the tropical response.

\subsection{Eddy Dissipation and BD Circulation}

[19] The principle of downward-control [Haynes et al., $1991]$ is used to demonstrate the impact of the dissipation of convectively generated eddies (see Figure 2a) on the tropical lower stratospheric BD circulation (Figure 3). According to downward-control, EP divergence exerts a local poleward force which connects vertically downward; the individual poleward forces and downward connections of a given EP divergence pattern superpose and thereby yield the eddy-driven BD circulation.

[20] The present study refers to downward-control in the simple sense mentioned above. Calculations of an eddydriven BD circulation via downward-control would be questionable since a significant portion of the modeled tropical lower stratospheric anomalous EP divergence (Figure 2a) occurs equatorward of $20^{\circ} \mathrm{N}$, where downwardcontrol may not apply in a strict sense [McIntyre, 1998].

[21] The anomalous BD circulation (REF minus SCN, Figure 3) is robust throughout most parts of the presented atmospheric section, six of six difference pairs displaying near-identical patterns (not shown). Only the patch of positive isolines at $35^{\circ} \mathrm{N}$ poleward is dominated by noise. Note that Figure 3 contains information on both mass circulation strength and direction which precludes a straightforward representation of robustness.

[22] There are distinct regions of anomalous tropical upwelling and anomalous tropical/subtropical downwelling which form an anomalous BD cell. Considering downwardcontrol, the cell's spatial extent as well as distribution of intensity and direction (Figure 3) roughly match the pattern of tropical anomalous EP divergence (Figure 2a); the subtropical pattern of negative isolines above $80 \mathrm{hPa}$ fits into this picture as it refers to significant directional changes of the absolute BD circulations for REF and SCN. Time-wise, too, there is consistency, since the strength and extent of the anomalous BD cell mirror the annual cycle of tropical EP divergence (not depicted). SST-induced changes in tropical lower stratospheric EP divergence hence alter the BD circulation locally via convective eddy generation in the troposphere. Further support for this conclusion is associated with the robustness of the whole causal chain, from stronger convective eddy generation due to higher tropical SSTs, via enhanced eddy dissipation to the anomalous BD cell.

[23] The anomalous BD cell (REF minus SCN) corresponds to intensified upwelling occurring equatorward of $15^{\circ} \mathrm{N}$ for REF, and to more poleward-directed transport northward of $15^{\circ} \mathrm{N}$; the latter anomaly implies a leakier summer hemispheric tropical pipe, similar to results presented by Rind et al. [2002].

[24] Finally, the anomalous BD cell matches the modeled anomaly of ozone concentrations and temperatures (not depicted): in the lower stratosphere, both anomalous quantities display a distinct minimum in the tropics, the region where the transport intensifies. For the E39/C simulations presently analyzed, World Meteorological Organization [2007, section 5.3.7] already mention this minimum in anomalous ozone.

\section{Summary and Conclusion}

[25] The present CCM study demonstrates for the first time that higher tropical SSTs in a warmer climate can change the tropical lower stratospheric BD circulation in the summer hemisphere via the deep-convective generation of upward propagating quasi-stationary eddies. The upper lid of $\mathrm{E} 39 / \mathrm{C}$, centered at $10 \mathrm{hPa}$, is unlikely to interfere since the tropical eddy dissipation enhancement mostly occurs at levels lower than $50 \mathrm{hPa}$.

[26] The mechanism is relevant during the period June to September in the northern hemisphere, and during December to March in the southern hemisphere. As a consequence, it modulates the tropical lower stratospheric BD circulation during eight months of the year, lowering tropical lower stratospheric ozone concentrations and temperatures for the warmer climate. 
[27] It is worth emphasizing that the mechanism investigated neither affects regions poleward of the summer hemisphere subtropics, nor affects the winter hemisphere. However, enhanced tropical deep convection may not only amplify the local generation of upward propagating quasistationary internal eddies, but also strengthen the generation of poleward propagating external eddies [e.g., Garcia and Salby, 1987]. The latter eddies could be able to enter the winter-hemispheric extratropical stratosphere and intensify the BD circulation there. Related effects on the winter hemisphere stratosphere by changes in tropical convection have been studied in the context of the El Niño/Southern Oscillation [e.g., Brönnimann et al., 2006, and references therein].

[28] Acknowledgments. The authors wish to thank Volker Grewe, Sigrun Matthes and Veronika Eyring for doing the model runs, and the ECHAM team for helpful discussions. They thank Eugene C. Cordero for constructive suggestions, and acknowledge Hella Garny for the proofreading. They also thank the European Commission for funding the project SCOUT-O3 (within the 6th framework programme).

\section{References}

Barsugli, J. J., S.-I. Shin, and P. D. Sardeshmukh (2006), Sensitivity of global warming to the pattern of tropical ocean warming, Clim. Dyn., 27, 483-492, doi:10.1007/s00382-006-0143-7.

Boehm, M. T., and S. Lee (2003), The implications of tropical Rossby waves for tropical tropopause cirrus formation and for the equatorial upwelling of the Brewer-Dobson circulation, J. Atmos. Sci., 60, 247-261.

Brönnimann, S., et al. (2006), The 1986-1989 ENSO cycle in a chemical climate model, Atmos. Chem. Phys., 6, 4669-4685.

Butchart, N., et al. (2006), Simulations of anthropogenic change in the strength of the Brewer Dobson circulation, Clim. Dyn., 27, 727-741, doi:10.1007/s00382-006-0162-4.

Chen, P. (2001), Thermally forced stationary waves in a quasigeostrophic system, J. Atmos. Sci., 58, 1585-1594.

Chen, P., M. P. Hoerling, and R. M. Dole (2001), The origin of the subtropical anticyclones, J. Atmos. Sci., 58, 1827-1835.

Dameris, M., et al. (2005), Long-term changes and variability in a transient simulation with a chemistry-climate model employing realistic forcing, Atmos. Chem. Phys., 5, 2121-2145.

Dameris, M., S. Matthes, R. Deckert, V. Grewe, and M. Ponater (2006), Solar cycle effect delays onset of ozone recovery, Geophys. Res. Lett., 33, L03806, doi:10.1029/2005GL024741.

Eyring, V., et al. (2007), Multimodel projections of stratospheric ozone in the 21 st century, J. Geophys. Res., 112, D16303, doi:10.1029/2006JD008332.
Fomichev, V. I., et al. (2007), Response of the middle atmosphere to $\mathrm{CO}_{2}$ doubling: Results from the Canadian Middle Atmosphere Model, J. Clim., 20, $1121-1144$.

Forster, P. M., G. Bodeker, R. Schofield, S. Solomon, and D. Thompson (2007), Effects of ozone cooling in the tropical lower stratosphere and upper troposphere, Geophys. Res. Lett., 34, L23813, doi:10.1029/ 2007 GL031994.

Garcia, R. R., and M. L. Salby (1987), Transient response to localized episodic heating in the tropics. Part II: Far-field behavior, J. Atmos. Sci., 44, 499-532.

Haynes, P. H., et al. (1991), On the 'downward control' of extratropical diabatic circulations by eddy-induced mean zonal forces, J. Atmos. Sci., $48,651-680$.

Horinouchi, T., et al. (2003), Tropical cumulus convection and upwardpropagating waves in middle-atmospheric GCMs, J. Atmos. Sci., 60, $2765-2782$.

Intergovernmental Panel on Climate Change (2001), Climate Change 2001-The Scientific Basis, Cambridge Univ. Press, New York.

Kerr-Munslow, A. M., and W. A. Norton (2006), Tropical wave driving of the annual cycle in tropical tropopause temperatures. Part I: ECMWF analyses., J. Atmos. Sci., 63, 1410-1419.

McIntyre, M. E. (1998), Breaking waves and global-scale chemical transport in the Earth's atmosphere, with spinoffs for the Sun's interior, Progr Theor. Phys., 130, suppl., 137-166.

Rayner, N. A., D. E. Parker, E. B. Horton, C. K. Folland, L. V. Alexander, D. P. Rowell, E. C. Kent, and A. Kaplan (2003), Global analyses of sea surface temperature, sea ice, and night marine air temperature since the late nineteenth century, J. Geophys. Res., 108(D14), 4407, doi:10.1029/ 2002JD002670.

Rind, D., J. Lerner, J. Perlwitz, C. McLinden, and M. Prather (2002), Sensitivity of tracer transports and stratospheric ozone to sea surface temperature patterns in the doubled $\mathrm{CO}_{2}$ climate, J. Geophys. Res., 107(D24), 4800, doi:10.1029/2002JD002483.

Stott, P. A., et al. (2006), Transient climate simulations with the HadGEM1 climate model: Causes of past warming and future climate change, $J$. Clim., 19, 2763-2782.

Thompson, D. W. J., and S. Solomon (2005), Recent stratospheric climate trends as evidenced in radiosonde data: Global structure and tropospheric linkages, J. Clim., 18, 4785-4795.

Wang, H., and M. Ting (1999), Seasonal cycle of the climatological stationary waves in the NCEP-NCAR reanalysis, J. Atmos. Sci., 56, $3892-$ 3919.

World Meteorological Organization (2007), Scientific Assessment of Ozone Depletion: 2006, Global Ozone Res. Monit. Proj. Rep., vol. 50, Geneva.

M. Dameris and R. Deckert, Deutsches Zentrum für Luft- und Raumfahrt, Institut für Physik der Atmosphäre, Oberpfaffenhofen, D-82234 Wessling, Germany, (martin.dameris@dlr.de; rudolf.deckert@dlr.de) 